\title{
A Festa Universitária como Prática Empreendedora: Economíadas em São Paulo
}

\section{The Universitarian Celebration as an Integrating and Entrepreneurial Practice: Economíadas in São Paulo}

\author{
Rodrigo Guimarães Motta \\ Pontifícia Universidade de São Paulo - PUC-SP - Brasil \\ rodrigo-motta@uol.com.br \\ ORCID: 0000-0002-5331-0294 \\ Maria Amélia Jundurian Corá \\ Universidade Federal de Alagoas - UFAL - Brasil \\ mariaamelia@gmail.com \\ ORCID: 0000-0002-1366-3626 \\ Iara Cristina de Fátima Mola \\ Pontifícia Universidade de São Paulo - PUC-SP - Brasil \\ iaramola@gmail.com \\ ORCID: 0000-0003-4761-9030
}

Submetido em 18/10/2018; Aprovado em 02/12/2018

\begin{abstract}
Resumo
Concebidas pelos alunos de Administração da Fundação Getúlio Vargas (FGV), as Economíadas - evento aqui tomado na condição de uma grande festa universitária - são realizadas anualmente pelos estudantes das melhores universidades de Administração, Economia e Contabilidade do Estado de São Paulo. Dado que são eles os responsáveis pela sua organização, este estudo partiu do pressuposto de que, ao oferecerem aos alunos a oportunidade de experienciarem uma vivência organizacional, as Economíadas se configurariam numa oportunidade capaz de estimular o perfil empreendedor dos universitários que dela participam. Assim, o objetivo deste trabalho formulou-se pelo interesse em compreender se e como essa organização poderia vir a fomentar o desenvolvimento das habilidades empreendedoras no público estudantil. Orientando-se por um conjunto de características empreendedoras a partir da perspectiva comportamentalista, foram analisados os conteúdos dos depoimentos de dois alunos da FGV que, entre outras participações, atuaram na organização das Economíadas em 2017. Os resultados permitiram não apenas validar o pressuposto inicial, evidenciando diversas características empreendedoras depreendidas desses relatos, como ainda permitiram identificar um grande envolvimento exteriorizado por eles - o que pode indicar que as Economíadas também se configurem como uma ferramenta promotora de integração e de identidade cultural entre os discentes. Ao se debruçar sobre um dos potenciais impactos de uma festa universitária ainda não estudada no meio acadêmico, este trabalho espera ter contribuído para fomentar a pesquisa em torno desse tipo de evento, inclusive na condição de recurso para a ampliação dos programas de ensino de empreendedorismo nas universidades, ao delegar seu preparo aos próprios alunos.
\end{abstract}

Palavras-chave: Economíadas. Festas Universitárias. Festas. Empreendedorismo. Empreendedorismo jovem.

\section{Abstract}

Conceived by students from the Administration course at Fundação Getúlio Vargas (FGV), the Economíadas - an event considered here as a great university celebration - is held annually by students from the best universities of Administration, Economics and Accounting of the State of São Paulo. Since their students are the ones responsible for its organization, this study assumes that, by offering students the chance of enjoying an organizational experience, the Economíadas is an opportunity capable of stimulating the entrepreneurial profile of those university students taking part in it. Thus, the objective of this work was formulated by the interest in understanding if and how such organization could foster the development of entrepreneurial skills in students. Guided by a set of entrepreneurial characteristics 
from a behaviorist perspective, the contents of testimonies of two FGV students were analyzed. These students, among other participations, were involved in the organization of the Economíadas in 2017. The results allowed not only to validate the initial assumption, evidencing several entrepreneurial characteristics derived from these reports, but also to identify the close involvement expressed by them which may indicate that the Economíadas also constitutes a tool promoting integration and cultural integrity among the student body. By focusing on one of the potential impacts of a university celebration that has not yet been studied in the academic world, this paper hopes to have contributed to foment research about this type of event, and even as a resource to develop programs on entrepreneurship in universities by delegating their organization to students.

Keywords: Economíadas. University Parties. Parties. Entrepreneurship. Young Entrepreneurship.

\section{Introdução}

Relevante dentro e fora do contexto acadêmico, cada vez mais o tema empreendedorismo e suas ramificações - a exemplo do empreendedorismo jovem - despertam interesse do público universitário e sua adesão à atividade empreendedora. Prova dessa realidade pode ser encontrada nos dados da última pesquisa Global Entrepreneurship Monitor (GEM), aplicada no Brasil pelo Serviço Brasileiro de Apoio às Micro e Pequenas Empresas (Sebrae) e pelo Instituto Brasileiro de Qualidade e Produtividade (IBQP). De acordo com os dados coletados de março a julho de 2018, a adesão de jovens entre 18 e 24 anos aumentou entre os empreendedores iniciais em $22,2 \%$, tendo havido um aumento da participação dos empreendedores com ensino superior completo em aproximadamente 10\% (Sebrae/IBPQ, 2018).

Na visão dos especialistas consultados pela pesquisa, três pontos podem ser destacados como positivos no que tange ao desenvolvimento do empreendedorismo no País: a vocação do brasileiro para empreender, a dinâmica do mercado brasileiro (oportunidades de negócio) e os programas governamentais. Quanto aos chamados "pontos limitantes" para o próprio empreendimento, eles elencaram as políticas governamentais (nas quais se encontra, por exemplo, o excesso de burocracia), a escassez de apoio financeiro (sobretudo para os empreendimentos iniciais) e a precariedade do sistema educacional básico. Acerca deste último item, mais especificamente, esses especialistas recomendam a ampliação dos programas de ensino de empreendedorismo, "aumentando o escopo de atuação desde os níveis mais básicos de educação (ensino primário) até os níveis mais elevados (pós-graduação)", bem como a criação de programas diferenciados "para trabalhar com comportamentos, com técnicas, com competências e nos mais diferentes setores da economia" (Sebrae/IBPQ, 2018).

Ampliando um pouco mais esta breve contextualização, foi encontrada a Pesquisa Empreendedorismo nas Universidades Brasileiras, uma correalização Sebrae/Endeavor Brasil ${ }^{1}$ em 2017. Segundo ela "a universidade deve potencializar e inspirar o empreendedorismo, o sonho grande e a inovação no aluno", sendo que, entre os principais problemas e dificuldades enfrentados pelo público estudantil, constam os fatos de que (i) "as universidades não têm uma estrutura que apoie a jornada completa do empreendedor", de que (ii) "a universidade está desconectada do mercado" e de que (iii) "a atuação da universidade não estimula a inovação e o sonho grande nos alunos" (Sebrae Nacional, 2017), muito embora esses mesmos alunos valorizem iniciativas empreendedoras em sua universidade. Nela, constatase que 6 em cada 10 universitários pensam em empreender.

Diante de números tão significativos associados ao interesse pelo empreendedorismo - inclusive por parte dos mais jovens com ensino superior completo -, dos desafios que ainda se verificam no sistema educacional e das próprias limitações apontadas em relação à atuação das universidades foi que, para o presente artigo, privilegiou-se o estudo das Economíadas, um evento universitário que aqui também é tomado na condição de festa esportiva e, ainda, de festa universitária. Isto porque, não obstante se tratar de um acontecimento cuja primeira finalidade se volta às competições esportivas entre as faculdades que o promovem, trata-se, hoje, de uma celebração cujo alcance é tão grande entre os universitários que dela participam que chega a se estender para além das quadras, dos campos, das piscinas e dos tatames nos quais as disputas se concretizam. Trata-se, portanto, de uma grande festa na qual as disputas entre as oito faculdades estão diretamente associadas a toda a preparação das baterias universitárias, a toda a animação das torcidas, assim como às festas específicas que ocorrem ao longo do próprio evento.

\footnotetext{
${ }^{1}$ Conforme a sua própria apresentação institucional, a Endeavor é uma organização global sem fins lucrativos que trabalha para que empreendedores de alto impacto tenham condições de exercer todo seu potencial (Endeavor Brasil, 2019).
} 
Concebidas pelos alunos de Administração da Fundação Getúlio Vargas (FGV) em 1991, as Economíadas são realizadas anualmente pelos estudantes de universidades de Administração, Economia e Contabilidade do Estado de São Paulo. A atuação desses estudantes nesse empreendimento tanto pode se dar pela sua participação como atletas quanto pela sua participação como organizadores/colaboradores - isto sem contar, claro, aqueles que comparecem ao evento na condição de espectadores/torcedores. Também é possível que essa atuação abranja tanto seu desempenho como atletas quanto seu exercício como organizadores desse grande evento, havendo diversos alunos que assumem ambas as frentes, a exemplo dos dois participantes desta pesquisa.

Uma vez que são eles os responsáveis pela sua organização, este estudo parte do pressuposto de que, ao oferecerem aos alunos a oportunidade de experienciarem uma vivência organizacional, as Economíadas se configurariam numa oportunidade capaz de estimular o perfil empreendedor dos jovens universitários que dela participam. 0 objetivo deste trabalho, portanto, formula-se pelo interesse em compreender se e como a organização de uma festa universitária como as Economíadas pode vir a efetivamente fomentar o desenvolvimento de características empreendedoras no público estudantil, promovendo, assim, a sua necessária "conexão" com a prática empreendedora no mercado de trabalho.

Conquanto toda festa também tenha como pressuposto o exercício da organização em algum nível, o que se verifica é que, embora a possibilidade de serem estudadas sob enfoques diversos, as festas designadas "universitárias" ainda não representam uma temática acerca da qual sejam encontrados outros estudos. Na Scientific Electronic Library Online (SciELO), por exemplo, a pesquisa realizada a partir do descritor "festa universitária" não localizou qualquer documento, sendo que o mesmo sucedeu para com "festa esportiva. Na Plataforma Sucupira, por sua vez, na qual se encontra hoje disponibilizado o catálogo de teses e dissertações da Coordenação de Aperfeiçoamento de Pessoal de Nível Superior (CAPES), a consulta a partir dos mesmos descritores - "festa universitária" e "festa esportiva"- também não identificou qualquer registro para cada uma das expressões.

Desta forma, além de se deter nos efeitos de uma festa ainda não estudada no meio acadêmico, enfocando sua potencial contribuição para a atividade empreendedora dos jovens que a viabilizam, este trabalho espera ainda contribuir para fomentar o debate em torno das festas universitárias entre aqueles que pesquisam sobre as festas em geral e, sem dúvida, entre aqueles que venham a pesquisar sobre as festas universitárias em específico.

Este é um estudo de natureza qualitativa, no qual é adotado o modelo etnográfico associado à análise de conteúdo, cujas análises contemplaram os depoimentos dados por dois alunos da FGV enquanto alunos dessa instituição, associados da atlética a ela filiada e organizadores das Economíadas no ano de 2017. Para desenvolvê-lo, seguiu-se a seguinte estrutura: a segunda seção discorre, em linhas gerais, acerca do que é empreendedorismo e de quais as características atribuídas ao perfil empreendedor; na terceira seção, são contextualizadas as Economíadas a partir da sua estreita relação com a Atlética da FGV; na quarta seção, detalham-se os procedimentos para que se pudesse viabilizá-la; na quinta seção, analisam-se e discutem-se os resultados das análises dos depoimentos, chegando-se, assim, às conclusões efetuadas pelos pesquisadores e às referências bibliográficas que embasaram este estudo.

\section{Do empreendedorismo ao perfil empreendedor: algumas definições e principais característi-} cas

Mais do que um conceito ou uma prática, o empreendedorismo tornou-se um campo. De acordo com Filion (1999, p. 6), "nos anos 80, o campo do empreendedorismo expandiu-se e espalhou-se para várias outras disciplinas. Organizações e sociedades foram forçadas a buscar novas abordagens para incorporarem [sic] as rápidas mudanças tecnológicas à sua dinâmica". A esse respeito, Souza (2005) apresenta os diversos campos de estudos sobre empreendedorismo, expandindo-o para as áreas social, econômica, política e comportamental. Existem pesquisadores que defendem, inclusive, a viabilidade do empreendedorismo dentro das próprias empresas já estruturadas (Chang, Chang \& Chen, 2017).

No que diz respeito ao universo do empreendedor, em especial, Filion (1999) chama atenção para o fato de que, na literatura, a confusão acerca da definição do termo é notável, tendo em vista que essa definição será feita pelos pesquisadores em conformidade com a própria área do conhecimento na qual se situam. Para ele próprio, "o empreendedor é uma pessoa criativa, marcada pela capacidade de atingir alguns objetivos e que mantém um alto nível de consciência do ambiente em que vive, usando-a para detectar oportunidades de negócios" (Filion, 1999, p. 19). Particularidades à parte, no entanto, o estudioso considera que são encontradas semelhanças em cada disciplina. 
Para os economistas, por exemplo, empreendedores são aqueles que combinam recursos, trabalho, materiais e ativos para tornar seu valor maior que antes; são também aqueles que introduzem mudanças, inovações e uma nova ordem. Cantillon e Say (apud Filion, 2000, p. 7) tomavam os empreendedores como "pessoas que aproveitavam as oportunidades com a perspectiva de obterem [sic] lucros, assumindo os riscos inerentes". Considerado o "pai do empreendedorismo", Say foi o primeiro a lançar os pilares desse campo de estudo, embora tenha sido Schumpeter (1984) o real responsável pelo seu lançamento, associando claramente o empreendedorismo à inovação.

As correntes psicológicas de estudo do empreendedorismo, por sua vez, remetem a discussão para as características pessoais do empreendedor, bastante focadas na necessidade de realização. Do ponto de vista comportamental, ser empreendedor significa tomar iniciativa, organizar mecanismos sociais e econômicos para transformar recursos e situações em algo prático, aceitando o risco e o fracasso. Já para a psicologia, empreendedora é a pessoa impulsionada pela necessidade de obter ou conseguir algo, experimentar, realizar ou fugir da autoridade de outros.

Para Chanlat (1995), a carreira empreendedora é aquela cujo foco está no indivíduo, na possibilidade de sucesso baseado em talentos e capacidades individuais e em que se tem como elemento central a criação de novos valores, produtos e serviços, sendo a criatividade e a capacidade de inovação os seus principais recursos. Colbari (2008) reitera essa visão ao considerar que:

O espírito é componente do capital humano; está relacionado ao desenvolvimento das potencialidades humanas, o que, no presente, significa capacidade de gerar conhecimento, de inovar, de transformar conhecimento em riqueza, de desenvolver a cooperação e de cultivar os ideais e as práticas democráticas. 0 empreendedor não pode ser construído, mas pode ser motivado a construir-se por meio da interiorização de novos padrões de comportamento e atitude. Nessa construção a emoção se sobrepõe à razão, pois não se aprende de forma cognitiva aquilo que é um fenômeno cultural. Nesta subversão do racionalismo cartesiano, a emoção é o combustível para desencadear comportamentos como é o caso da busca da realização de um sonho (Colbari, 2008, p. 11).

Paiva Junior (2004) acrescenta ainda que os empreendedores - consciente ou inconscientemente - baseiam-se em determinantes psicossociais, tendendo a manifestar atitudes congruentes com suas crenças e valores, no intuito de minimizar os possíveis conflitos internos e externos, reduzindo assim a sua dissonância cognitiva.

Como é possível verificar diante do exposto e na própria literatura dedicada ao empreendedorismo, conceituá-lo é uma tarefa complexa, devido à amplitude de enfoques dados pelos autores que estudam o tema. De todo modo, o que se sabe é que pensar em empreendedorismo significa, sobretudo, observar o agente empreendedor. Isso porque as práticas e estratégias adotadas por ele fazem com que a cultura organizacional seja própria e viva, ou seja, que responda a uma dinâmica em um campo marcado pelo papel do empreendedor no contexto sociocultural escolhido por ele para atuar.

Dado o objetivo apresentado neste estudo, no qual se busca compreender se e como a organização de uma grande festa como as Economíadas pode se revelar uma prática fomentadora das características empreendedoras nos alunos que dela participam, a base teórica adotada privilegia a perspectiva comportamental, interessando aqui os aspectos que configuram o perfil do empreendedor. Isto porque, para que a análise possa ser conduzida ao encontro do objetivo, buscar-se-á identificar, por meio dos depoimentos dados pelos participantes, como essas características se revelam na sua fala e por meio da sua atuação nas Economíadas em 2017.

Quadro 1 - Características dos empreendedores - consoante os comportamentalistas.

\begin{tabular}{|l|l|l|}
\hline 1 Inovação & 9. Otimismo & $\begin{array}{l}\text { 17. Tolerância à ambiguidade e à in- } \\
\text { certeza }\end{array}$ \\
\hline 2. Liderança & 10. Orientação para os resultados & 18. Iniciativa \\
\hline 3. Riscos moderados & 11. Flexibilidade & 19. Capacidade de aprendizagem \\
\hline 4. Independência & $\begin{array}{l}\text { 12. Habilidade para conduzir situa- } \\
\text { ções }\end{array}$ & $\begin{array}{l}\text { 20. Habilidade na utilização de recur- } \\
\text { sos }\end{array}$ \\
\hline 5. Criatividade & 13. Necessidade de realização & 21. Sensibilidade a outros \\
\hline 6. Energia & 14. Autoconsciência & 22. Agressividade \\
\hline 7. Tenacidade & 15. Autoconfiança & 23. Tendência a confiar nas pessoas \\
\hline 8. Originalidade & 16. Envolvimento a longo prazo & $\begin{array}{l}\text { 24. Dinheiro como medida de desem- } \\
\text { penho }\end{array}$ \\
\hline
\end{tabular}

Fonte: Filion (2000, p. 9). 
As características em questão, reunidas por Hornaday (1982), Meredith, Nelson e Neck (1982) e Timmons (1978) e reproduzidas por Filion (2000, p. 9), são tomadas aqui como categorias mobilizadas para análise, conforme será explicitado na quarta seção. Elas seriam as mais frequentemente atribuídas aos empreendedores pelos pesquisadores comportamentalistas, sendo que, por "comportamentalistas", Filion (1999) designa psicólogos, sociólogos e outros especialistas do comportamento humano:

Posto se tratar de um quadro em que constam palavras e expressões comuns ao vocabulário de uso geral e sobre as quais as próprias fontes consultadas não se detêm individualmente, estes autores consideraram que as características apresentadas são autoexplicativas, dispensando, assim, a necessidade de que fossem pontuadas uma a uma. Além disso, consideraram ainda que, uma vez que elas viessem a ser identificadas na fala de cada um dos entrevistados, o contexto depreendido da leitura desses depoimentos também contribuiria, por si mesmo, para que os efeitos práticos associados a cada uma dessas características ganhassem ainda mais aplicabilidade.

\section{Economíadas: das origens até a viabilização do evento nos dias atuais}

Geridas pelos próprios alunos, a principal responsabilidade das associações atléticas acadêmicas consiste em coordenar a prática esportiva da faculdade da qual fazem parte, sendo este o caso da Associação Atlética Acadêmica Getúlio Vargas (AAAGV) ou simplesmente "Atlética", como referido por Santos (2015, p. 54). É através das atividades organizadas pela Atlética "que os GVnianos traduzem seu sentimento pela EAESP [Escola de Administração de Empresas de São Paulo] na quadra, no campo, na piscina, no tatame".

Embora a AAAGV seja hoje uma associação que contempla a EAESP, a EESP (Escola de Economia de São Paulo) e a EDESP (Escola de Direito Empresarial de São Paulo) - todas ligadas à Fundação Getúlio Vargas de São Paulo -, na década de 1980, quando se oficializou sua fundação, a entidade ainda se restringia à EAESP.

No que concerne ao seu caráter esportivo, muitos dos alunos associados jogavam em clubes da cidade de São Paulo ou vinham de cidades do interior das quais traziam consigo a cultura do esporte. Somados os esforços dos seus associados, a AAAGV foi crescendo como entidade e, se os campeonatos internos entre as equipes das demais faculdades paulistas já eram algo comum, em 1988 deu-se início aos jogos realizados contra instituições localizadas fora de São Paulo.

Além do nome oficial - o qual é acompanhado por todo um processo de governança alinhado com a legislação brasileira -, as atléticas são entidades que também se utilizam de símbolos para ser identificadas. A adesão ao símbolo, todavia, se estende para além da mera identificação: serve como instrumento motivador para que os estudantes participem delas. Não por acaso é que Santos (2015, p. 56) se refere ao símbolo da AAAGV como "um dos mais significativos da entidade".

Quando a diretoria de esportes do Diretório Acadêmico Getúlio Vargas (DAGV) se tornou a AAAGV, em 1987, a expectativa do seu fundador, Eduardo Quilici, era a de construir algo semelhante aos Jogos Jurídicos - evento em que se promoviam competições entre faculdades dessa área acadêmica e que eram realizadas em cidades do interior de São Paulo, o que permitia que os estudantes também confraternizassem entre si durante os dias de competição. E foi a terceira gestão da AAAGV, liderada por Rodrigo Guimarães Motta, que realizou a primeira iniciativa coordenada para atingir esse objetivo: a realização da GV x FEA (Faculdade de Economia e Administração da Universidade de São Paulo), seguido da GV x MACK (Faculdade de Economia e Administração do Mackenzie). Após o sucesso dessas iniciativas, essas três faculdades se uniram e, em 1991, fundaram a Liga Atlética Acadêmica de Ciências Econômicas (LAACE), convidando outras escolas de Economia e Administração de São Paulo para a I Economíadas, evento realizado nesse mesmo ano na cidade de Bauru, em São Paulo.

Durante a década de 1990, as Economíadas ocorreram de forma semelhante ao primeiro evento, com competições entre as faculdades realizadas em uma cidade do interior de São Paulo. Os participantes do evento eram os atletas de cada instituição e alguns amigos e aficionados dos esportes de cada uma das faculdades. Enquanto os eventos reuniam algumas centenas de participantes, as festas aconteciam principalmente nos bares e nas próprias danceterias e casas de show locais, nas quais os universitários se encontravam para comemorar as proezas do dia.

Foi na década de 2000 que Eduardo Quilici se associou a Alfredo Motta, ex-aluno, publicitário e diretor de polo-aquático da GV para que, juntos, profissionalizassem o evento, organizando-o como um produto e captando recursos para patrociná-lo junto a empresas que tinham interesse em divulgar e 
conectar suas marcas com o público universitário. Nesse contexto, surgiu a Na Mosca Marketing Universitário, a qual, em conjunto com a LAACE, passou a captar patrocínios e apoios de empresas como CocaCola, Ambev, Nutrimental, Ferrero, Unilever.

Dos recursos obtidos pela Na Mosca e pela LAACE é que surgiram as tendas nos eventos, nas quais ocorriam refeições, "aquecimentos" (momento no qual os universitários tomavam uma bebida antes das festas) e shows.

Fortalecido o caráter social das Economíadas, surgiram outros fenômenos, como as baterias universitárias, que passaram a animar a torcida nos jogos da faculdade a que cada uma estava vinculada. Conforme Santos (2015, p. 56), "sem dúvida, a bateria é um dos componentes essenciais para dar força às equipes e levantar a torcida durante as competições. Hoje, a Tatubola é uma das maiores baterias universitárias de São Paulo". Na Figura 1, a Bateria durante o evento de 2017; na Figura 2, o registro da torcida nesse mesmo ano:

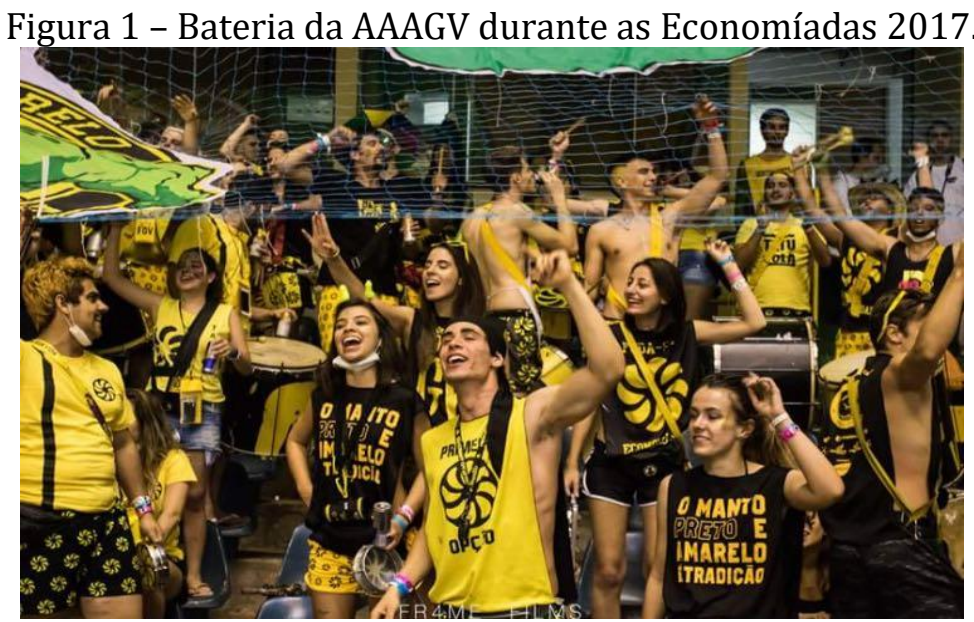

Fonte: Arquivo dos autores (2017).

Figura 2 - Torcida da AAAAGV durante as Economíadas 2017.

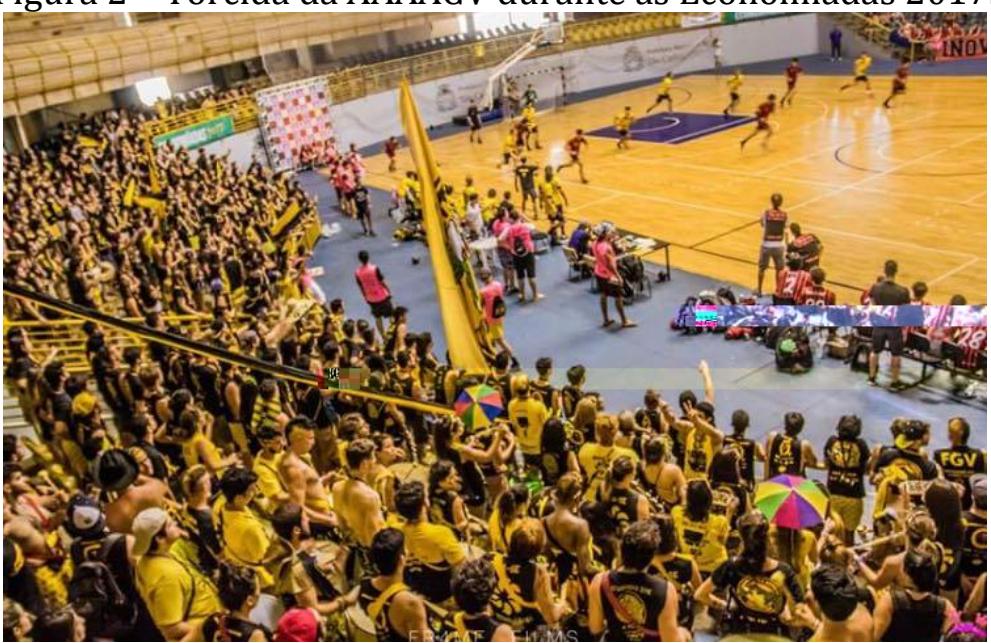

Fonte: Arquivo dos autores (2017).

Foi nos anos 2000 que as Economíadas passaram a ser frequentadas não mais por centenas, mas por milhares de estudantes universitários que vão torcer pelos times das suas respectivas faculdades e também participar das festas, como a GVJada, a Jacatenda e a Giabólica.

Com o tempo, o sucesso desse modelo de parceria se consolidou, ganhando a adesão de mais patrocinadores e com cada vez mais frequentadores, de modo que, hoje, ainda que as Economíadas sejam o principal evento esportivo-festivo das faculdades de Economia e Administração, existem também as Economíadas Caipiras, que reúnem faculdades de Administração do interior de São Paulo e contemplam eventos temáticos ao longo do ano, organizados pelas atléticas e pela LAACE.

Além disso, multiplicaram-se as agências que ajudam as atléticas individualmente e a Liga a organizarem esses eventos e as próprias Economíadas. As próprias cidades que passaram a reconhecer o 
potencial econômico do evento disputam entre si o direito de realizá-lo.

Assim é que as Economíadas chegam ao final da década de 2010 como um evento consolidado e clássico para os estudantes das faculdades de Economia e Administração, com a mesma dimensão e atração que outros eventos que lhes são similares.

Em sua edição de 2017, por exemplo, realizada de 2 a 5 de novembro na cidade de São Carlos, em São Paulo, as Economíadas contaram com a participação dos estudantes da Faculdade Mackenzie, FEA USP, ESPM, FEA PUC, INSPER, FECAP e PUCAMP, além da própria FGV, disputando 12 modalidades esportivas (basquete, futebol de campo e salão, natação, vôlei, rugby, xadrez, jiu-jitsu, judô, tênis de mesa e campo e handebol). A expectativa era de movimentar em média R\$ 5 milhões no comércio local, nos setores de hotelaria, gastronomia, transporte e comércio em geral, além de terem sido geradas duas mil vagas temporárias de emprego durante o evento, que foram distribuídas entre barmans, seguranças, equipes de limpeza, eletricistas, carregadores, staff de alimentação e técnicos de estrutura $(G 1,2017)$. No que diz respeito aos resultados obtidos, a FGV foi a grande campeã, conquistando seu primeiro título geral (Figura 3).

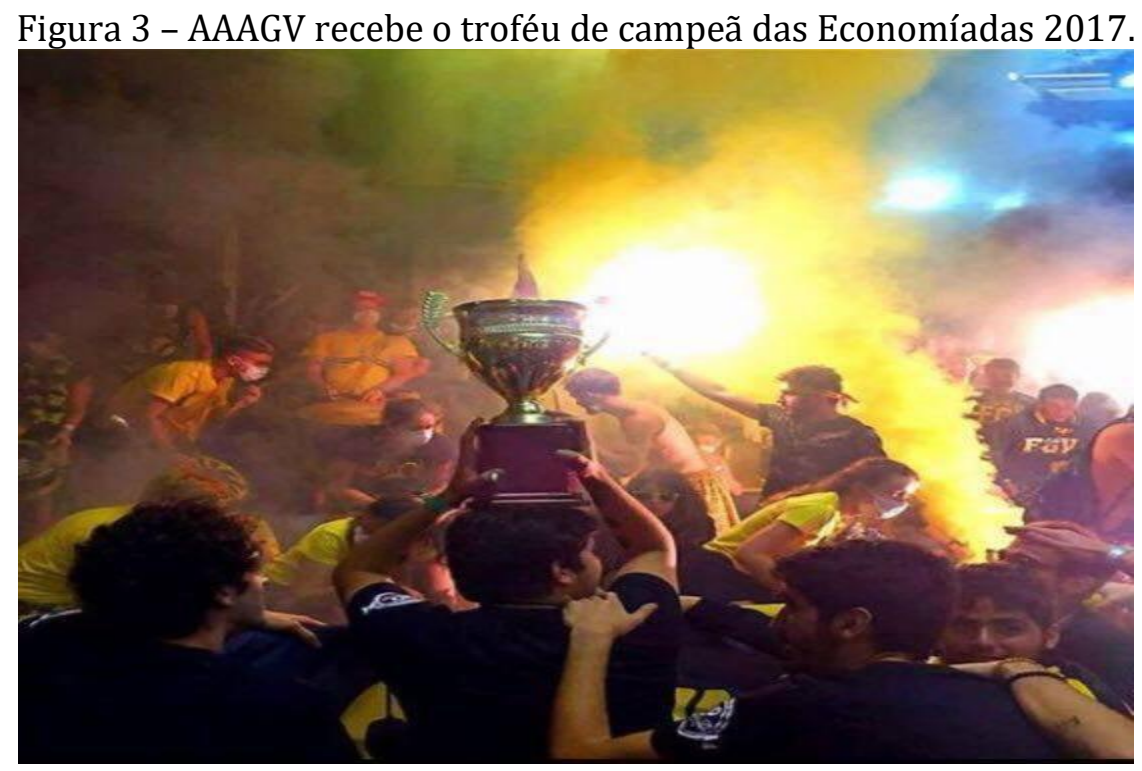

Fonte: Arquivo dos autores (2017).

\section{Percurso metodológico}

Visando a compreender se e como a organização de uma festa universitária como as Economíadas pode vir a fomentar o desenvolvimento de características empreendedoras para os estudantes, este estudo se define como uma pesquisa de natureza pura e abordagem qualitativa, na qual se privilegiou o projeto etnográfico, uma vez que "a etnografia focaliza em todo um grupo que compartilha uma cultura" (CRESWELL, 2013, p. 82) e que os pesquisadores, portanto, descrevem e interpretam os padrões compartilhados e aprendidos de valores, comportamentos, crenças e linguagem de um grupo.

Conforme Creswell (2013), a pesquisa etnográfica se define por, entre outros aspectos, focar no desenvolvimento de uma descrição complexa e completa da cultura de um grupo. Além disso, o pesquisador etnográfico busca padrões (ou rituais, comportamentos sociais costumeiros ou regularidade) das atividades mentais ou materiais do grupo, sendo que, neste artigo, em conformidade com o que se verificou na seção 2 , interessam os comportamentos associados às características empreendedoras.

Para essa busca, sabe-se que a teoria desempenha um papel importante, envolvendo também um amplo trabalho de campo. Assim, concomitantemente ao desenvolvimento das bases teóricas nas quais se apoiou este estudo, empreendeu-se igualmente um amplo trabalho de campo, voltado inicialmente a um projeto de estudo maior, a partir do qual este artigo se desdobrou.

Em razão desse projeto, para que fosse possível "mergulhar" na vida desses participantes, observá-los e entrevistá-los, elegeu-se a observação participante. Os jogos aconteceram em diferentes localidades dentro de São Carlos, sendo que, neles, as atléticas participaram das modalidades já elencadas na seção anterior.

Em conformidade com a relevância identificada pelo pesquisador, as entrevistas que complementaram a etnografia foram filmadas, assim como várias fotografias foram tiradas durante essa imersão, 
enriquecendo a composição desse material e lhe conferindo sua característica fílmica.

Foram selecionados dois depoimentos para que fosse realizada a exemplificação das categorias empreendedoras apontadas por Filion (2000), considerando como critério de seleção dois estudantes da FGV associados à Atlética e cuja experiência estivesse diretamente relacionada à organização do evento, sendo uma delas correspondente à vivência organizacional por meio de uma função tático-operacional e, a outra, por meio de um cargo de diretoria (Quadro 2).

Quadro 2 - Dados dos participantes desta pesquisa.

\begin{tabular}{|c|c|c|c|c|c|}
\hline Identificação & $\begin{array}{c}\text { Gê- } \\
\text { nero }\end{array}$ & Curso & $\begin{array}{c}\text { Atuação } \\
\text { Profissio- } \\
\text { nal }\end{array}$ & $\begin{array}{c}\text { Representou a facul- } \\
\text { dade em alguma mo- } \\
\text { dalidade esportiva? }\end{array}$ & $\begin{array}{c}\text { Posição ocupada na orga- } \\
\text { nização }\end{array}$ \\
\hline $\begin{array}{c}\text { Respondente } \\
1 \text { (R1) }\end{array}$ & $\begin{array}{c}\text { Mascu- } \\
\text { lino }\end{array}$ & $\begin{array}{c}\text { Administra- } \\
\text { ção }\end{array}$ & $\begin{array}{c}\text { Não traba- } \\
\text { lha }\end{array}$ & Sim & $\begin{array}{c}\text { Função tático-operacional } \\
\text { - logística }\end{array}$ \\
\hline $\begin{array}{c}\text { Respondente } \\
\text { (R2) }\end{array}$ & $\begin{array}{c}\text { Femi- } \\
\text { nino }\end{array}$ & $\begin{array}{c}\text { Administra- } \\
\text { ção }\end{array}$ & $\begin{array}{c}\text { Não traba- } \\
\text { lha }\end{array}$ & Sim & Função estratégica \\
- diretoria
\end{tabular}

Fonte: Elaborado pelos autores (2019).

Os depoimentos dados pelos alunos serão reproduzidos na seção seguinte tal como foram registrados pelos participantes. Para analisá-los, foi utilizada a análise de conteúdo (Bardin, 2016), aplicando-se como categorias de análise as características pontuadas no Quadro 1 deste estudo.

Entre os aspectos comuns aos depoimentos, constatou-se que ambos foram elaborados no último dia do evento e após o anúncio da conquista do título-geral pela FGV, embora estes não tenham sido critérios para a delimitação realizada.

\section{Análise e discussão}

Passando aos depoimentos, cada um deles será apresentado conforme as especificações tratadas na seção 4 e analisado de acordo com os critérios já assinalados no item anterior e explicitados na seção 2, a começar pela fiel reprodução do depoimento dado por R1:

"O econo é a alma do atleta gvniano, nosso objetivo, o motivo de treinarmos tanto, mesmo com tantas outras coisas para fazer. [...] Como atleta e atleticano, posso dizer que sempre tive orgulho de quem nós somos, e que nosso peso como faculdade e atlética era enorme, por isso não aceitava que a GV não tivesse nenhum econo, foi o que me motivou a entrar para os jogos, tanto para competir como para organizar, e graças a esse sentimento (que acho que a maioria dos atletas compartilham) conseguimos conquistar nosso $1^{\circ}$ econo. 0 econo me deu uma experiência que nunca achei que conseguiria adquirir, fiquei responsável pela logística dos ônibus, que foi uma experiência exaustiva, porém muito gratificante, aprendi a lidar com pessoas, resolver problemas o mais rápido possível, e tudo isso, sob uma pressão e stress gigantescos."

Tal como é possível depreender desse primeiro depoimento, bem como da informação contida na penúltima coluna do Quadro 2, R1 foi um dos alunos da FGV e associados da Atlética que, além da organização do evento, também representaram a faculdade em alguma das modalidades esportivas.

Em se dividindo seu depoimento em duas partes, verifica-se que a primeira evidencia sua atuação como atleta e, mais particularmente, como atleta da FGV, com cuja Atlética R1 também se identifica. Já na transição para a segunda parte, no intervalo em que o entrevistado passa do seu orgulho à sua motivação (motivação "tanto para competir como para organizar"), observa-se, na sua justificativa, a necessidade de realização: "[...] não aceitava que a GV não tivesse [ganhado] nenhum econo [...]". Além disso, quando o aluno estabelece a relação entre "esse sentimento" (que ele não chega a nomear, mas que se volta ao "orgulho" de ser aluno/atleta/atlético da FGV) e a conquista do primeiro título-geral da FGV nas Economíadas, ele permite que se entreveja o investimento de energia, de otimismo e de autoconfiança para que fosse possível viabilizar essa realização, assim como a demonstração de tenacidade: para conquistar a primeira Economíadas, foi preciso ser persistente, tenaz.

Ao relatar sua experiência como organizador do evento, R1 se refere a uma "experiência que nunca achou que conseguiria adquirir", do que se pode inferir que, não fosse a oportunidade dada pelas Economíadas para que pudesse vivenciar essa responsabilidade, o próprio estudante não vislumbrava a possibilidade de obtê-la fora dali.

Encarregado da logística dos ônibus - que, por exemplo, conduzem os universitários das tendas para os espaços onde serão disputados os jogos -, R1 relata "uma experiência exaustiva", mas imediata- 
mente seguida de um conectivo reformulador, isto é, de um operador discursivo que remete a uma conclusão contrária ao sentido argumentativo até então indicado: "[...] foi uma experiência exaustiva, porém muito gratificante [...]".

Já ao exemplificar em que havia consistido essa experiência, R1 inicia a sequência com o seguinte registro: "[...] aprendi a lidar com pessoas [...]", remetendo, portanto, a uma capacidade de aprendizagem que, embora não pormenorizada, pode implicar - simultaneamente ou não - tolerância à ambiguidade e à incerteza e sensibilidade a outros. Depois, registra: "[aprendi a] resolver problemas o mais rápido possível [...]", o que pode implicar, para além da própria capacidade de aprendizagem e dos problemas associados às relações com as pessoas, a habilidade para conduzir situações e até mesmo a habilidade na utilização de recursos, uma vez que R1 administrava a logística dos ônibus. Por fim, arremata: "e [aprendi] tudo isso, sob uma pressão e stress gigantescos", o que pode ser interpretado como uma demonstração de persistência (de tenacidade) diante dos enormes desafios de pressão e da situação de estresse, bem como uma orientação para os resultados, já que, apesar da "pressão e stress gigantescos", R1 considera essa experiência "muito gratificante".

No mais, é possível estimar se, no depoimento dado pelo aluno, também não estaria subentendida uma demonstração do que vem a ser autoconsciência, tendo em vista que ele expressa com clareza aquilo que diz respeito a si mesmo e ao seu aproveitamento no que tange à sua ativa participação na preparação das Economíadas.

Assim, das 24 características dos empreendedores elencadas no Quadro 1 pelos comportamentalistas, o depoimento de R1 permite que sejam distinguidas estas 11: necessidade de realização, energia, otimismo, autoconfiança, tenacidade, capacidade de aprendizagem, tolerância à ambiguidade e à incerteza, sensibilidade a outros, habilidade para conduzir situações, habilidade na utilização de recursos e autoconsciência.

Para além delas, no entanto, cumpre ainda destacar a identificação exteriorizada por R1 em relação à faculdade e à Atlética da GV. Note-se que, além de declarar abertamente sua preocupação e seu orgulho para com a instituição e a entidade ("[...] sempre tive orgulho de quem nós somos, e que nosso peso como faculdade e atlética era enorme [...]"), há, de forma menos evidente, a apropriação de uma pessoa do discurso que, no lugar de falar por si mesma nesse momento, enuncia em nome de um coletivo, revelando, portanto, seu envolvimento: "nosso objetivo", "treinarmos tanto", "nós somos", "nosso peso", "conseguimos", "nosso 1ํ econo".

Logo, embora não seja possível apontar as Economíadas como obrigatoriamente sendo, por si mesmas, a razão pela qual R1 se identifica tanto com a faculdade e com a Atlética, pode-se deduzir, contudo, que elas também se configuram como meio de integração entre os próprios alunos. Além disso, ao serem tomadas como "a alma do atleta gvniano", transformam-se ainda num elemento impulsionador para que as características empreendedoras sejam postas em prática no desempenho desses discentes, tanto na condição de atletas como na condição de seus organizadores.

Passando-se agora ao depoimento de R2, tem-se:

"O economíadas foi um teste pra mim no quesito de perseverança como diretora da atlética e atleta. Teste de foco e concentração, é um ano inteiro dependente de 4 dias. E o que mais motivou a minha participação nas Economíadas foi sentir que todo o trabalho do ano foi posto à prova e finalmente vivemos aquilo para o qual tanto nos preparamos, tanto como atleta como atlética. Como diretora da atlética, o economíadas me ensinou a ser firme e lutar com respeito pelo que favorece minha faculdade, além de perseverança. Me ensinou a como exercer uma posição de poder e como ceder e perceber que você não sabe tudo mesmo que saiba de muito. Em outras palavras, o economíadas, por ter tido a incrível oportunidade de experienciá-lo como diretora da atlética, me forneceu uma inteligência emocional que eu acredito que vai me favorecer, e muito, durante minha experiência profissional."

A exemplo do que se verificou no primeiro depoimento, tal como é possível depreender deste segundo e da informação contida na penúltima coluna do Quadro 2, R2 foi uma das alunas da FGV e associadas da Atlética que, além da organização do evento, representaram a faculdade em alguma das modalidades esportivas. Neste caso, entretanto, o relato referente à experiência na organização do evento sobrepõe o relato referente à sua participação como atleta: em "O economíadas foi um teste pra mim no quesito de perseverança como diretora da atlética e atleta", a própria menção como diretora da Atlética antecede o registro relativo à condição de atleta.

Centrada, então, nessa experiência, a primeira frase registrada por R2 revelaria autoconsciência de sua parte, ao avaliar o propósito da responsabilidade assumida ("[...] um desafio para mim [...]"] e, 
concomitantemente, qual o desafio particular que se lhe impunha: um teste "no quesito perseverança" e de "foco e concentração". A autoconsciência se manifesta ainda quando, tal como R1, a aluna assinala suas aprendizagens ("[...] Me ensinou a como exercer uma posição de poder e como ceder e perceber que você não sabe tudo mesmo que saiba de muito [...]") e, ainda, estabelece uma relação entre a "inteligência emocional" por ela apreendida e a estimativa acerca da sua futura atuação profissional no mercado lembrando que ela ainda não trabalha.

Além disso, posto que, para R2, tratou-se de um "teste" à sua "perseverança", pode-se se subentender que, ao permanecer no seu posto de diretora da entidade, R2 "venceu" o teste, dando provas de sua tenacidade. A tenacidade, a propósito, emerge também uma segunda vez no seu depoimento por meio da repetição do seu termo equivalente ("perseverança"), quando a entrevistada explicita sua aprendizagem.

Antes, porém, na continuidade do trecho relacionado à sua motivação, R2 considera: "[...] finalmente estávamos vivendo aquilo para o qual tanto nos preparamos, tanto como atleta como atlética [...]", do que se pode inferir uma necessidade de realização e de orientação para os resultados. Isto porque era desejável que o trabalho realizado ao longo do ano fosse "posto à prova" e que, de toda a preparação, sobreviessem os resultados.

Salientando o cargo desempenhado, R1 reflete: "[...] Como diretora da atlética, o economíadas me ensinou a ser firme e lutar com respeito pelo que favorece minha faculdade [...]", afirmação da qual se pode depreender o desenvolvimento da autoconfiança ("ser firme e lutar" são ações que pressupõem alguma confiança em si mesmo), não bastasse a capacidade de aprendizagem.

Ao contar com a oportunidade de desempenhar o papel de diretora da Atlética, R2 permite entrever que a característica empreendedora da liderança não acompanhava o exercício da função, como se uma coisa necessariamente já implicasse a outra: a oportunidade lhe ensinou "[...] como exercer uma posição de poder e como ceder e perceber que você não sabe tudo mesmo que saiba de muito [...]", isto é, ensinou-lhe liderança (na sua "posição de poder") e sensibilidade a outros e habilidade para conduzir situações (não se tratava apenas de "ceder", mas de "como ceder"). E, especificamente no que diz respeito a "[...] perceber que você não sabe tudo mesmo que saiba de muito [...]", também pode estar subentendida a tendência a confiar nas pessoas, uma vez que se passe a considerar que, para além de si mesmo, também há outros que "sabem do que estão falando", sendo necessário confiar no conhecimento alheio.

Por fim, também à semelhança de R1, que se reporta a uma "experiência muito gratificante", R2 se refere a uma "incrível oportunidade", numa associação às Economíadas.

Assim, das 24 características dos empreendedores elencadas no Quadro 1 pelos comportamentalistas, o depoimento de R2 permite que sejam distinguidas estas 10: autoconsciência, tenacidade, necessidade de realização, orientação para os resultados, autoconfiança, capacidade de aprendizagem, liderança, sensibilidade a outros, habilidade para conduzir situações e tendência a confiar nas pessoas.

Para além delas, no entanto, cumpre ainda destacar a identificação exteriorizada por R1 em relação à faculdade e à Atlética da GV. Tal como no depoimento de R1, em "[...] finalmente vivemos aquilo para o qual tanto nos preparamos, tanto como atleta como atlética [...]", observa-se a mudança da pessoa discursiva, que passa do enunciador em primeira pessoa do singular à primeira pessoa do plural, denotando envolvimento: "vivemos", "nos preparamos". Neste caso, porém, diferentemente de R1, a incorporação do coletivo na própria fala não se detém somente na experiência como atleta: R2 registra ambas - "como atleta como atlética".

\section{Conclusão}

Partindo do pressuposto de que, ao oferecem aos alunos a oportunidade de experienciarem uma vivência organizacional, as Economíadas se configurariam numa oportunidade capaz de estimular o perfil empreendedor dos jovens universitários que dela participam, os resultados aqui obtidos apontam para a validação dessa possibilidade levantada inicialmente. Pelo que se pôde depreender de cada um dos registros mediante a análise de conteúdo, as Economíadas fomentam, de fato, o desenvolvimento de características empreendedoras no público estudantil, respondendo-se aí à hipótese manifestada pelo se. Afinal, das 24 características empreendedoras elencadas pelos comportamentalistas e dispostas no Quadro 1, os entrevistados apresentaram, respectivamente, 11 e 10 identificadas na análise - sendo aqui 
necessário considerar que ambos não estavam situados no contexto do mercado, mas no contexto universitário, bem como que não se pretendeu esgotar qualquer possibilidade de análise.

Conquanto cada contexto tenha suas particularidades, importa acrescentar, todavia, que a vivência organizacional correspondente à preparação das Economíadas aproximou-se bastante - se é que não replicou - da vivência organizacional inerente ao próprio mercado, na qual se sabe serem comuns os desafios enfrentados pelos profissionais no que diz respeito a situações de "exaustão", de problemas que exigem soluções rápidas e de "pressão e estresse gigantescos" (tal como relatado por R1), assim como de "testes" de "perseverança", "foco" e "concentração" (tal como relatado por R2).

Nesse sentido, portanto, é que se constata, por meio do exercício de cada qual na atividade a que foi designado, a articulação entre a prática relativa à preparação da festa universitária e a prática relativa ao mercado, estabelecendo-se aí a "conexão" que muitas vezes os alunos não conseguem identificar. R2, por exemplo, que não atuava no mercado à época, explicita essa conexão que ela própria é capaz de visualizar entre uma coisa e outra ao escrever que, como diretora da Atlética, desenvolveu uma inteligência emocional que, segundo acreditava, a favoreceria - "e muito" - durante sua experiência profissional.

Embora os participantes desta pesquisa pertençam a gêneros diferentes e estivessem exercendo cargos igualmente distintos, verifica-se que, apesar das particularidades inerentes à atividade e à própria percepção de cada um, foram identificados aspectos comuns aos dois depoimentos. No que se refere à manifestação das características empreendedoras, em especial, seis delas foram apresentadas por ambos: necessidade de realização, tenacidade, autoconsciência, capacidade de aprendizagem, sensibilidade a outros, autoconfiança e habilidade para conduzir situações - aspectos que retroalimentam a perspectiva comportamental acerca da ação de empreender, que significa tomar iniciativa, organizar mecanismos sociais e econômicos visando a transformar recursos e situações em algo prático e aceitar tanto o risco quanto o fracasso.

Trata-se, então, da resposta à ordem do como: tomadas como um acontecimento que inspirava sua intensa motivação e sua própria preparação como organizadores e como atletas, as Economíadas suscitaram em R1 e em R2 o desenvolvimento de habilidades empreendedoras que eles desconheciam em si mesmos, mas que foram positivamente demonstradas quando cada um deles se viu responsável pelo desempenho de determinada função.

Nessa direção, embora nada se tenha pesquisado pormenorizadamente quanto às razões pelas quais esses participantes tanto se identificavam com a FGV, com a Atlética e/ou com as Economíadas, o que se constata ainda é que, para além das características empreendedoras previstas, os entrevistados expressaram não só toda sua satisfação com o título conquistado pela FGV, como também seu envolvimento com o próprio coletivo acadêmico em nome do qual por vezes enunciaram. Sob essa perspectiva, abrem-se possibilidades para novos estudos por meio dos quais se possa investigar, por exemplo, se as Economíadas também não se configurariam como prática integradora dos seus organizadores (e atletas) mediante o senso de pertencimento e/ou de identidade cultural que parece ser capaz de promover, inscrevendo-se na memória do grupo como um afeto coletivo.

Dado que as festas universitárias e suas contribuições não são um fenômeno estudado e que, não obstante se tratar de um evento consolidado e de relevante dimensão, as Economíadas são uma festa que nenhum pesquisador até então se propusera a estudar, este trabalho buscou suprir duas lacunas, quais sejam: a ampliação das perspectivas acerca da festa universitária como objeto de estudo (e como objeto de estudo no campo da Administração) em geral, e, em específico, o olhar sobre as Economíadas como uma festa capaz de contribuir, de fato, para o desenvolvimento das habilidades empreendedoras dos alunos que a organizam.

\section{Referências}

Bardin, L. (2016). Análise de conteúdo. São Paulo: Edições 70.

Cantillon, R. (1959). Essay on the nature of trade in general. Londres: Frank Cass.

Chang, Y. Y., Chang, Y. C. \& Chen, C. W. (2017). Transformational leadership and corporate entrepreneurship: cross level mediation moderation evidence. Leadership \& Organization Development Journal, (38), 6, 812-833.

Chanlat, J. F. (1995). Quais carreiras e para qual sociedade (I)? RAE - Revista de Administração de Empresas, $(35) 6,67-75$.

Colbari, A. L. (2008). Os desafios da formação de empreendedores na sociedade brasileira. In: Anais... 
XXV Simpósio de Gestão da Inovação Tecnológica, Brasília, DF, Brasil.

Creswell, J. W. (2013). Investigação qualitativa e projeto de pesquisa: escolhendo entre cinco abordagens. Porto Alegre: Penso.

Endeavor Brasil. Quem somos. Recuperado de https://endeavor.org.br/quem-somos/.

FGV. Escola de Administração de Empresas de São Paulo. Sobre a EAESP. Recuperado de https://eaesp.fgv.br/sobre-eaesp.

Filion, L. J. (1999). Empreendedorismo: empreendedores e proprietários-gerentes

de pequenos negócios. Revista de Administração, (34)2, 5-28. Recuperado de https://www.academia.edu/1168821/Empreendedorismo_empreendedores_e_propriet\%C3\%A1rios-gerentes_de_pequenos_neg\%C3\%B3cios.

Filion, L. J. (2000). Empreendedorismo e gerenciamento: processos distintos, porém complementares. RAE Light. RAE - Revista de Administração de Empresas, (7)3, 2-7. Recuperado de http://www.scielo.br/pdf/rae/v40n3/v40n3a13.pdf.

G1. (2017). Com jogos e shows, 'Economíadas' deve movimentar $R \$ 5$ milhões em São Carlos. Recuperado de https://g1.globo.com/sp/sao-carlos-regiao/noticia/com-jogos-e-shows-economiadas-deve-movimentar-r-5-milhoes-em-sao-carlos.ghtml.

Hisrich, R. \& Peters, M. P. (1996). Empreendedorismo. Porto Alegre: Bookman.

Hornaday, J. A. (1982). Research about living entrepreneurs. In Kent, C. A. et al (Orgs.). Encyclopedia of entrepreneurship (pp. 20-34). Englewood Cliffs: Prentice-Hall.

Meredith, G. G., Nelson, R. E. \& Neck, P. A. (1982). The practice of entrepreneurship. Geneva, International Labour Office.

Paiva Junior, F. G. (2004). O empreendedorismo na ação de empreender: uma análise sob o enfoque da fenomenologia sociológica de Alfred Schütz (Tese de Doutorado). Centro de Pós-Graduação e Pesquisas em Administração da UFMG, Belo Horizonte, Minas Gerais, Brasil.

Plataforma Sucupira. (2019). Recuperado de https://sucupira.capes.gov.br/sucupira/public/index.xhtml.

Santos, A. L. (2015). Amor Preto e Amarelo. GVExecutivo. Recuperado de http://bibliotecadigital.fgv.br/ojs/index.php/gvexecutivo/article/viewFile/49194/48007.

Say, J. B. (1983). Tratado de Economia Política. São Paulo: Abril Cultural.

Schumpeter, J. (1984). Capitalismo, socialismo e democracia. Rio de Janeiro: Zahar Editores.

SciELO. (2019). Scientific Electronic Library Online. Recuperado de http://www.scielo.org.

Sebrae Nacional (2017). O empreendedorismo nas universidades brasileiras. Educação Empreendedora. Recuperado de http://www.sebrae.com.br/sites/PortalSebrae/artigos/o-empreendedorismo-nas-universidades-brasileiras,6ad3352450608510VgnVCM1000004c00210aRCRD.

Sebrae/IBPQ (2018). GEM 2018 - Global Entrepreneurship Monitor. Recuperado de https://datasebrae.com.br/wp-content/uploads/2019/02/GEM-2018-Apresenta\%C3\%A7\%C3\%A3o-SEBRAE-Finalslide.pdf.

Souza, E. C. L. (2005). Empreendedorismo da gênese à contemporaneidade. In: Anais... EGEPE - Curitiba, Paraná, Brasil.

TIMMONS, J. A. (1978) Characteristics and role demands of entrepreneurship. American Journal of Small Business, (3)1, 5-17. 